\title{
Electrochemical Meaning of Cumulative Corrosion Rate for Reinforced Concrete in a Tropical Natural Marine Environment
}

\author{
Pedro Castro-Borges, Mercedes Balancán-Zapata, and Alexia Zozaya-Ortiz \\ Centro de Investigación y de Estudios Avanzados del IPN, Unidad Mérida, km. 6 Ant. Carr. A Progreso, 97310 Mérida, YUC, Mexico \\ Correspondence should be addressed to Pedro Castro-Borges; pcb1963@gmail.com
}

Received 18 August 2016; Revised 12 December 2016; Accepted 5 January 2017; Published 1 February 2017

Academic Editor: Michael Aizenshtein

Copyright (C) 2017 Pedro Castro-Borges et al. This is an open access article distributed under the Creative Commons Attribution License, which permits unrestricted use, distribution, and reproduction in any medium, provided the original work is properly cited.

\begin{abstract}
The objective of this paper is to discuss the meaning of cumulative corrosion rate $\left(i_{\mathrm{CCR}}\right)$ of reinforced concrete in a tropical marine microclimate of the Yucatan Peninsula identifying four stages that correspond to passivation, beginning of depassivation, breakdown and formation of subsequent corrosion layers, and nucleation and development of cracks. Sixty Portland cement concrete cylinders were exposed in a tropical marine environment at $50 \mathrm{~m}$ from the seashore. One-half of the samples had a reinforcing bar embedded at the center of the sample (corrosion measurements) and the other half was made with plain concrete (chloride measurements). Five water/cement $(\mathrm{w} / \mathrm{c})$ ratios and three times of curing (CT) were tested representing the common practices of this region. The corrosion rate was monitored using the linear polarization resistance technique $\left(R_{p}\right)$ which enables calculating the apparent and cumulative corrosion rate. Representative results indicated that $i_{\mathrm{CCR}}$ was effective not only to detect the beginning and duration of the reported stages but also to find the right influence of $\mathrm{CT}$ and $\mathrm{w} / \mathrm{c}$ ratios on the corrosion performance of reinforced concrete.
\end{abstract}

\section{Introduction}

Corrosion of reinforcing steel is one of the most important causes of reinforced concrete structures degradation [13]. The environment and climate change effects contribute also to the acceleration of this deterioration. The humidity, rainfall, and different concentrations of sea chloride ions in the environment enhance its deposition on the concrete surface and the degradation rate significantly depends on the seashore distance [4]. In the case of structures exposed in a marine environment, chloride ions are deposited on the surface of the concrete and penetrate until they reach the surface of the reinforcing steel, causing the breakdown of the passive layer [5]. Once reinforcing bar corrosion take place, corrosion products start to build up around the reinforcing bar, causing volumetric expansions that will result in concrete cover cracking after subsequent breakdown and formation of corrosion layers [6-8]. Apparent corrosion rate $\left(i_{\text {app }}\right)$ obtained through $R_{p}$ has been possibly the most useful technique to obtain information about depassivation of steel and propagation of corrosion.
Andrade and González [9] were the first authors to establish a range of corrosion rate $\left(0.1-0.5 \mu \mathrm{A} / \mathrm{cm}^{2}\right)$ where depassivation of reinforcement starts. However, sensibility of equipment, cell configurations, and natural data dispersion have made the interpretation of corrosion data before and after the depassivation state (initiation and propagation periods) difficult. With these limitations, the depassivation can only be recognized once corrosion has really started instead of when first data denote the beginning of the depassivation state. Then, formation and breakdown of subsequent corrosion layers cannot be easily detected. Actually, corrosion techniques have improved due to the digital age but precision depends mainly on mathematical treatment. With this in mind, cumulative corrosion rate has become a useful tool to know details of initiation and propagation periods. This tool has been reported formerly in this field by Andrade et al. [1013] and subsequently by Troconis De Rincón et al. and CastroBorges et al. [14, 15]. The reported information discussed by all of these authors contains not only the use of cumulative corrosion but also its interpretation in both natural and accelerated tests. However, it would be interesting to improve 


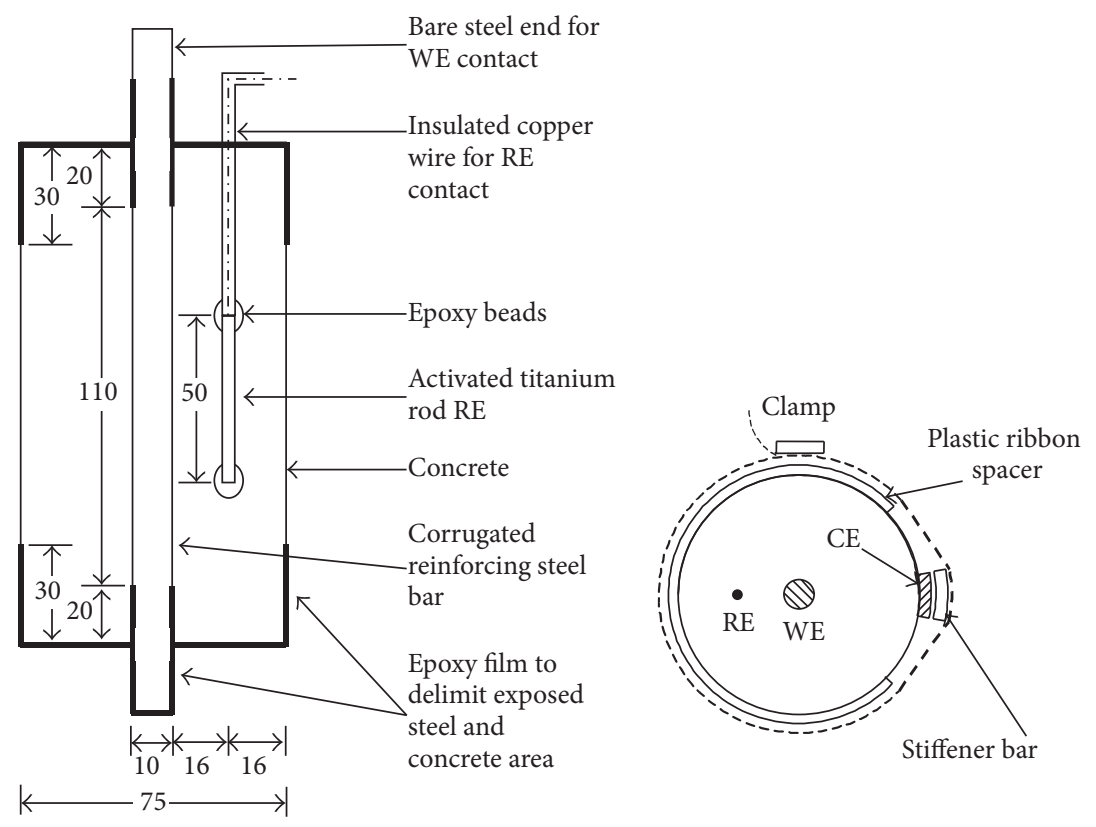

FIGURE 1: Specimen configuration.

the interpretation of $i_{\mathrm{CCR}}$ through more exposure conditions from different type of materials, but specially on identifying the exact initiation of the depassivation, the breakdown and formation of subsequent corrosion layers, and the nucleation and development of cracks, all of which are an important part of this paper. The objective of this paper is, then, to discuss the electrochemical meaning of $i_{\mathrm{CCR}}$ behavior of reinforced concrete exposed for about five years in a tropical marine environment.

\section{Experimental Procedure}

2.1. Materials and Sample Dimensions. ASTM Type I ordinary Portland cement (OPC) and crushed limestone aggregates were used for fabrication of concrete cylinders (diameter $\sim 75 \mathrm{~mm}$, height $\sim 150 \mathrm{~mm}$ ) (Figure 1). Plain concrete cylinders were used to determine 28-day compressive strength and chloride penetration during the experimental period. Typical number 3 deformed steel rebar $(\sim 0.4 \mathrm{wt} \%$ carbon content) was used to simulate reinforcement. Rebar sections were weighed before cylinder casting and section ends were protected with epoxy and adhesive tape. This limits the exposed area inside the concrete specimen and isolates any rebar areas directly exposed to the environment. Rebar sections were positioned axially within the cylinders and extended the entire length (Figure 1). A $50 \mathrm{~mm}$ activated titanium rod (ATR), characterized elsewhere, was used as a reference electrode for electrochemical measurements [16, 17]. For this study, it was calibrated versus a saturated calomel electrode (SCE). An epoxy coating layer was applied to the cylinder's ends to delimit concrete and steel exposure area (Figure 1). Concrete mixture proportions and phys$\mathrm{ical} / \mathrm{mech}$ anical properties of the hardened concrete have been published elsewhere [16-19]. A total of 60 cylinders were tested at $50 \mathrm{~m}$ from the seashore, in the Port of Progreso having two cylinders from each combination of plain and reinforced concrete for a total of 30 plain concrete and 30 reinforced concrete cylinders.

One of the most important parameters for defining concrete quality is the $\mathrm{w} / \mathrm{c}$ ratio [20]. A low $\mathrm{w} / \mathrm{c}$ ratio reduces concrete porosity, and concrete permeability to external agents (i.e., chlorides) decreases when porosity is low, improving its service life [21]. To study the effect of $\mathrm{w} / \mathrm{c}$ ratio on service life, concrete was made using five w/c ratios: $0.76,0.70,0.53,0.50$, and 0.46 .

Ratios as high as 0.70 and 0.76 are commonly used in the Yucatan Peninsula region, although public buildings in Mexico (i.e., schools, hospitals) are constructed using lower $\mathrm{w} / \mathrm{c}$ ratios $(0.53$ or 0.50$)$. The 0.46 ratio is still not commonly used in this region but was included in this study for comparative purposes since this value is frequently used in the relevant literature. Curing time periods for concrete structures in Mexico range from 1 day to 28 days, although 7 days is by far the most common CT period. This variable was tested at 1, 3, and 7 days, with two cylinders tested per each combination of $\mathrm{w} / \mathrm{c}$ ratio and $\mathrm{CT}$.

2.2. Environmental Exposure. Specimens had been exposed to the marine environment of Progreso's Port, located at the north coast of the Yucatan Peninsula $\left(21^{\circ} 18^{\prime} \mathrm{N}, 89^{\circ} 39^{\prime} \mathrm{W}\right)$, in Mexico, and are characterized as having a tropical humid climate. Specimens were placed about $50 \mathrm{~m}$ away from the seashore, on top of a roof (approximately $4 \mathrm{~m}$ above ground level). Both specimen types (plain and reinforced concrete cylinders) were oriented vertically. The carbon steel corrosivity category in this particular marine environment is higher than C5 (environment with $\tau_{4}$, time of wetness, or time that relative humidity is $\geq 85 \%$ and temperature $>30^{\circ} \mathrm{C}$ 
and $\leq 60^{\circ} \mathrm{C}$, between $2,500 \mathrm{~h} / \mathrm{y}$ and $5,500 \mathrm{~h} / \mathrm{y}$; atmospheric chloride concentration $300 \mathrm{mg} / \mathrm{m}^{2} \mathrm{~d}$ to $1,500 \mathrm{mg} / \mathrm{m}^{2} \mathrm{~d}$ ) with an average annual temperature of $26^{\circ} \mathrm{C}$ and average annual relative humidity of $79 \%[22,23]$. Chloride was not added to the concrete mixtures prior to specimen casting to ensure that any chloride contamination was due to natural exposure during the experimental period.

2.3. Corrosion Measurements. Rebar electrochemical properties were measured using an external conductive rubber counter electrode tightly attached to the concrete cylinders with aluminum clamps for each test (Figure 1). Electrochemical measurements were taken with a commercially available potentiostat/galvanostat/ZRA and included corrosion potentials $\left(E_{\text {corr }}\right)$ and apparent corrosion rates $\left(i_{\text {app }}\right)$ determined by using the linear polarization resistance $\left(R_{p}\right)$ technique $[24,25] . R_{p}$ was measured by applying $10 \mathrm{mV}$ in the cathodic direction from $E_{\text {corr }}$ at a $0.06 \mathrm{mV} / \mathrm{s}$ scan rate. Ohmic drop $\left(R_{s}\right)$ as a result of the high concrete resistivity was measured with a commercially available resistance meter. The adjusted $R_{p}$ estimates were then converted to apparent corrosion rate $\left(i_{\text {app }}\right)$ values using the following equation [9]:

$$
i_{\text {app }}=\frac{B}{R_{p}-R_{s}}
$$

where $B=0.026$ when the rebar exhibited corrosion activity (i.e., when rebar potentials were more negative than $-200 \mathrm{mV}$ versus CSE); or $B=0.052[9,24]$ when the rebar exhibited passive behavior (i.e., when rebar potentials were more positive than $-200 \mathrm{mV}$ versus CSE); and $R_{p}$ or $R_{s}$ are in $\Omega \cdot \mathrm{cm}^{2}$ (calculated via multiplication by the nominal rebar surface area $\sim 33 \mathrm{~cm}^{2}$ in contact with concrete). These measurements were taken every two to three months during the entire experimental period.

\section{Results and Discussion}

Figures 2-6 show the average (two specimens) $i_{\text {app }}$ (subsection (a)) and $i_{\mathrm{CCR}}$ (subsection (b) and (c)) values as a function of exposure time for the specimens at $50 \mathrm{~m}$ from the seashore exposure site, per each combination of $\mathrm{w} / \mathrm{c}$ ratio and CTs. After depassivation and as observed, all w/c ratio concrete showed apparent $i_{\text {app }}$ values higher than $0.5 \mu \mathrm{A} / \mathrm{cm}^{2}$, indicative of steel active corrosion (DURAR Network, 1997) [26]. Figures 2-6 show clear trends in terms of depassivation for both w/c ratios and CTs. Also, electrochemical results presented well defined trends: higher w/c ratio concrete presented higher $i_{\text {app }}$ values. The higher the CT, the bigger the reinforcing bar depassivation time $\left(i_{\text {app }}<0.5 \mu \mathrm{A} / \mathrm{cm}^{2}\right)$. But additional analysis is required with the data obtained from field measurements in order to obtain other important parameters like, for example, the corrosion initiation times as a function of $\mathrm{w} / \mathrm{c}$ ratio and distance from the seashore and the corrosion degradation. Because of that, it was decided to observe the possible contributions to the knowledge of the electrochemical behavior that the cumulative corrosion rate can provide and give an interpretation as discussed from here.
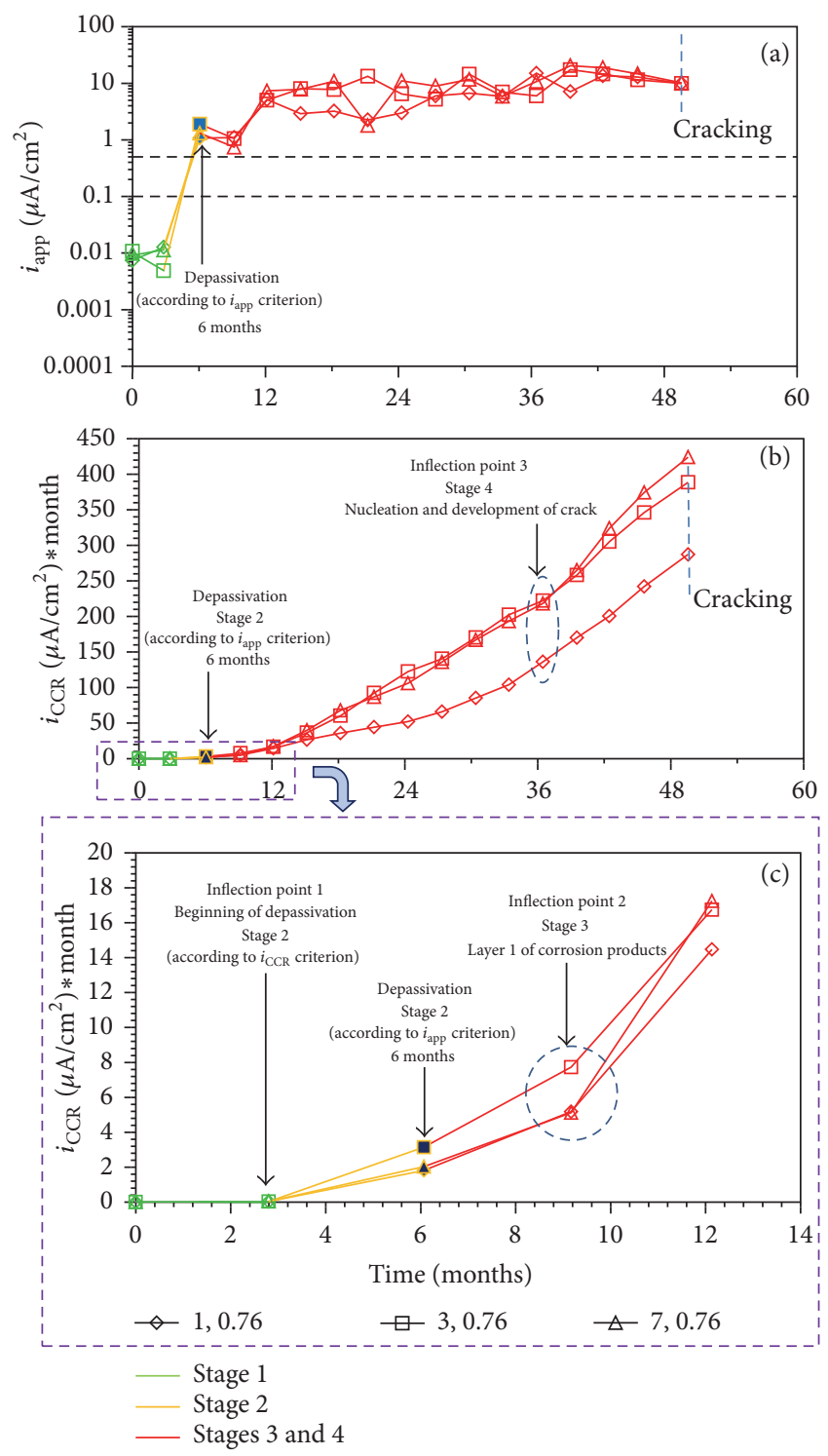

FIgURE 2: (a) Average apparent $i_{\text {corr }}$ and (b and c) cumulative $i_{\text {corr }}$ versus exposure time, $\mathrm{w} / \mathrm{c}$ ratio $=0.76$, and three CTs.

Figures 2-6 show the behavior of $i_{\text {app }}$ and $i_{\mathrm{CCR}}$ of the specimens exposed to the natural marine environment for 48 months or more. Each value is the average of 2 specimens.

There are some clear facts:

(a) The lower the $\mathrm{w} / \mathrm{c}$ ratio, the longer the depassivation period.

(b) In general, the lower the $\mathrm{w} / \mathrm{c}$ ratio, the longer the stay of $i_{\text {app }}$ at the transition zone. This means that more drift is detected between the active and the passive zone.

(c) In general, $i_{\mathrm{CCR}}$ was able to show the contribution of CT to the passivation period: the longer the CT, the longest the depassivation period.

(d) Despite a concrete cover close to $4 \mathrm{~cm}$, depassivation times are shorter than those normally reported in 

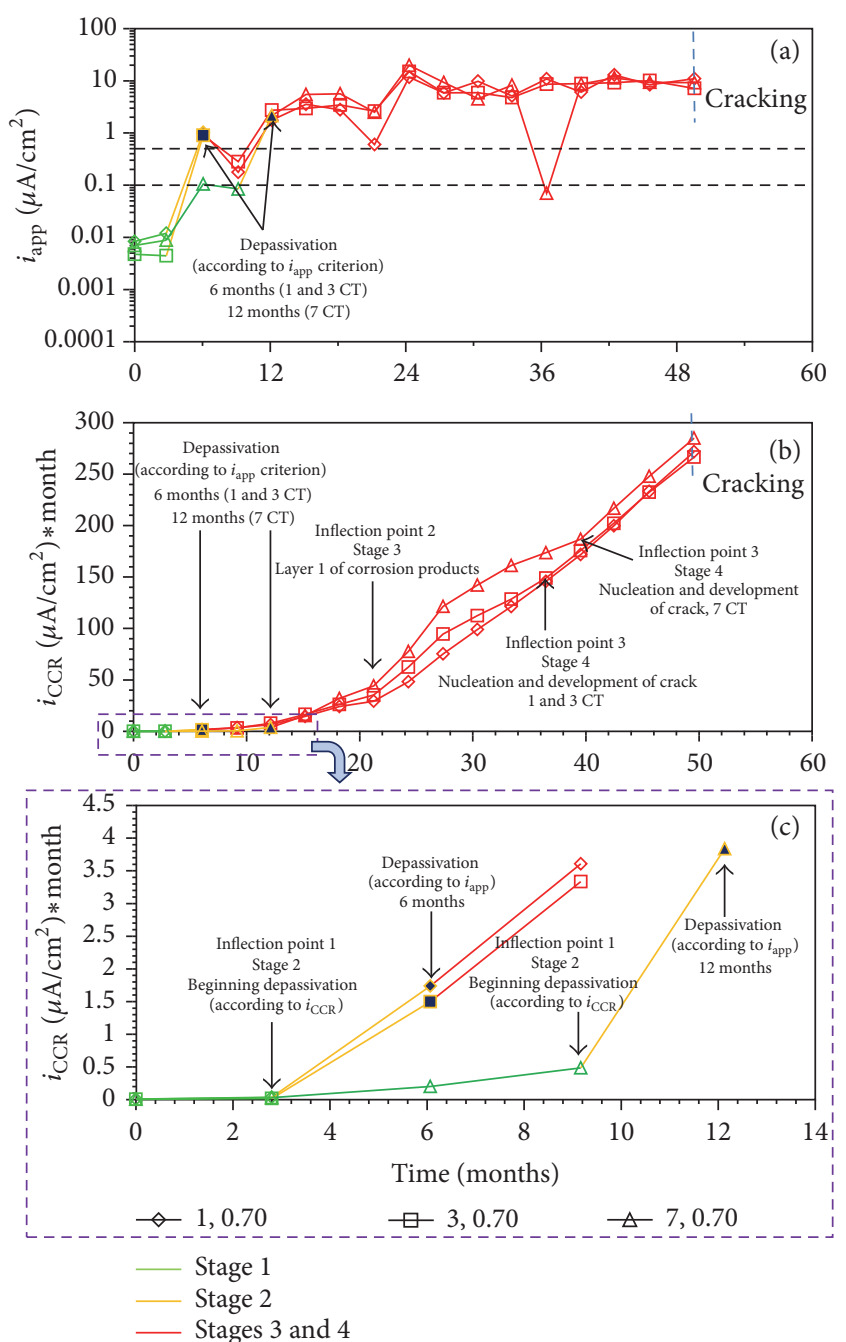

Figure 3: (a) Average $i_{\text {app }}$ and (b and c) $i_{\mathrm{CCR}}$ versus exposure time, $\mathrm{w} / \mathrm{c}$ ratio $=0.70$, and three CTs.

the literature. This was due to the following reasons [27-29]:

(i) High w/c ratios

(ii) High levels of fines content in aggregates

(iii) High porosity of the construction aggregates from this geographic area

(iv) High atmospheric aggressiveness (>C5).

The fact that depassivation can occur early but then nothing much happens for a long time (green on the exploded $i_{\mathrm{CCR}}$ plots), as shown in Figure 6, was proposed earlier [30], where the authors also gave physical reasons for this phenomenon.

(e) Figures 2-6 show inflection points on $i_{\mathrm{CCR}}$ that denote a noticeable change of tendency on $i_{\mathrm{CCR}}$. A number of points maintaining a constant tendency after the inflection point are better observed at lower w/c ratios.
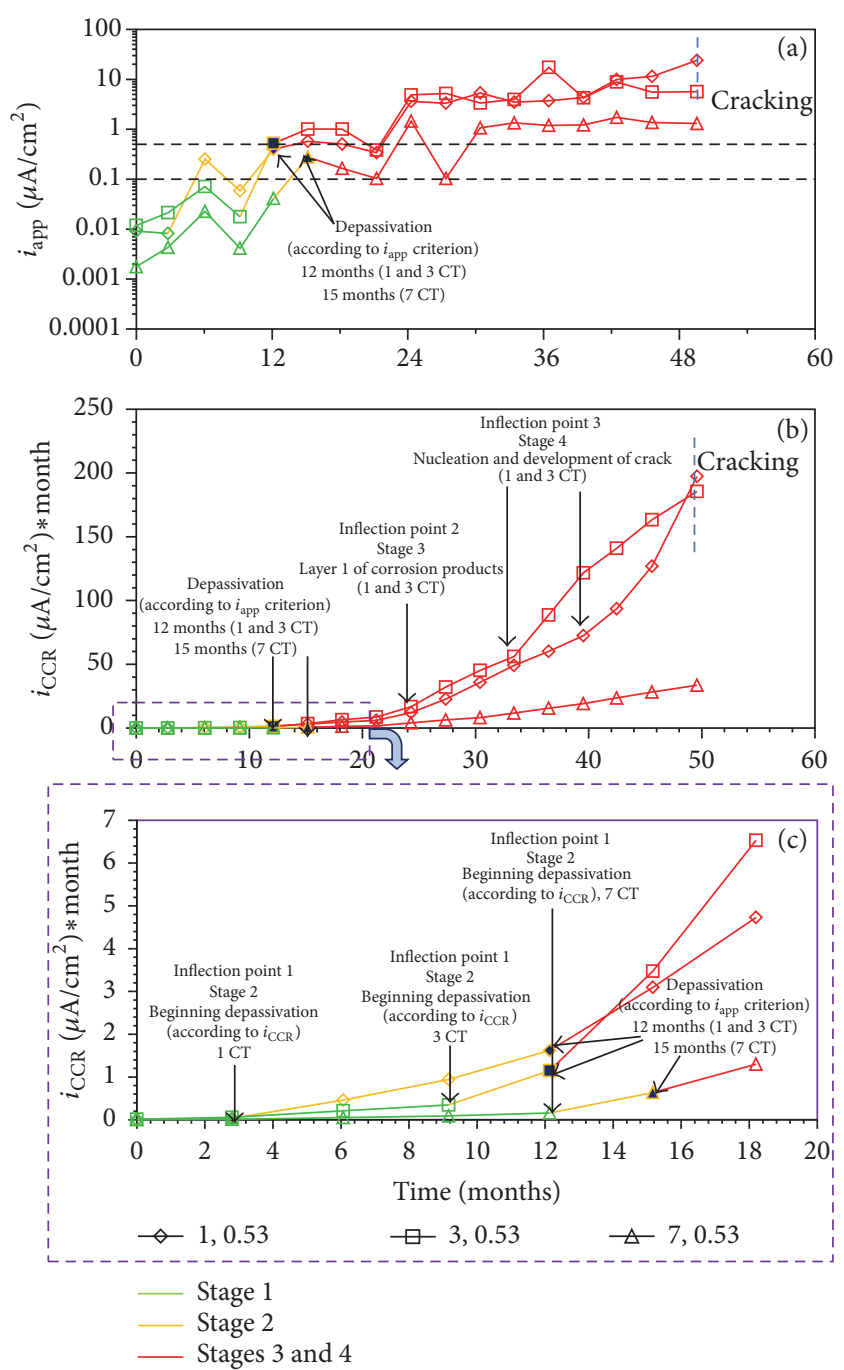

FIgURE 4: (a) Average $i_{\text {app }}$ and (b and c) $i_{\mathrm{CCR}}$ versus exposure time, $\mathrm{w} / \mathrm{c}$ ratio $=0.53$, and three CTs.

(f) Figures 2-6 show color thickness to denote the stages detected according to $i_{\mathrm{CCR}}$. This color was maintained in $i_{\text {app }}$ plots just to denote that depassivation begins before the detected one with the $i_{\text {app }}$ criterion.

(g) Figures 2-6 show four stages as defined below.

Stage 1 (passivation). At early stages of exposure to the marine environment, it is common that any specimen shows initial passivation, denoted by a passive layer. The electrochemical behavior, doing a follow-up of apparent corrosion, is distinguished by consistent and stable values below $0.1 \mu \mathrm{A} / \mathrm{cm}^{2}$. Passivation is stable if the $i_{\text {app }}$ values do not increase and remain with a trend below the threshold $\left(0.1-0.5 \mu \mathrm{A} / \mathrm{cm}^{2}\right)$ as shown in Figures $2(\mathrm{a})-6$ (a) with green thickness. This is clear in cumulative corrosion rate where a constant linear increase is observed in subsections (b) and (c) of Figures 2-6 in green color. In practical terms, the observed inflection point denotes the beginning of the depassivation 

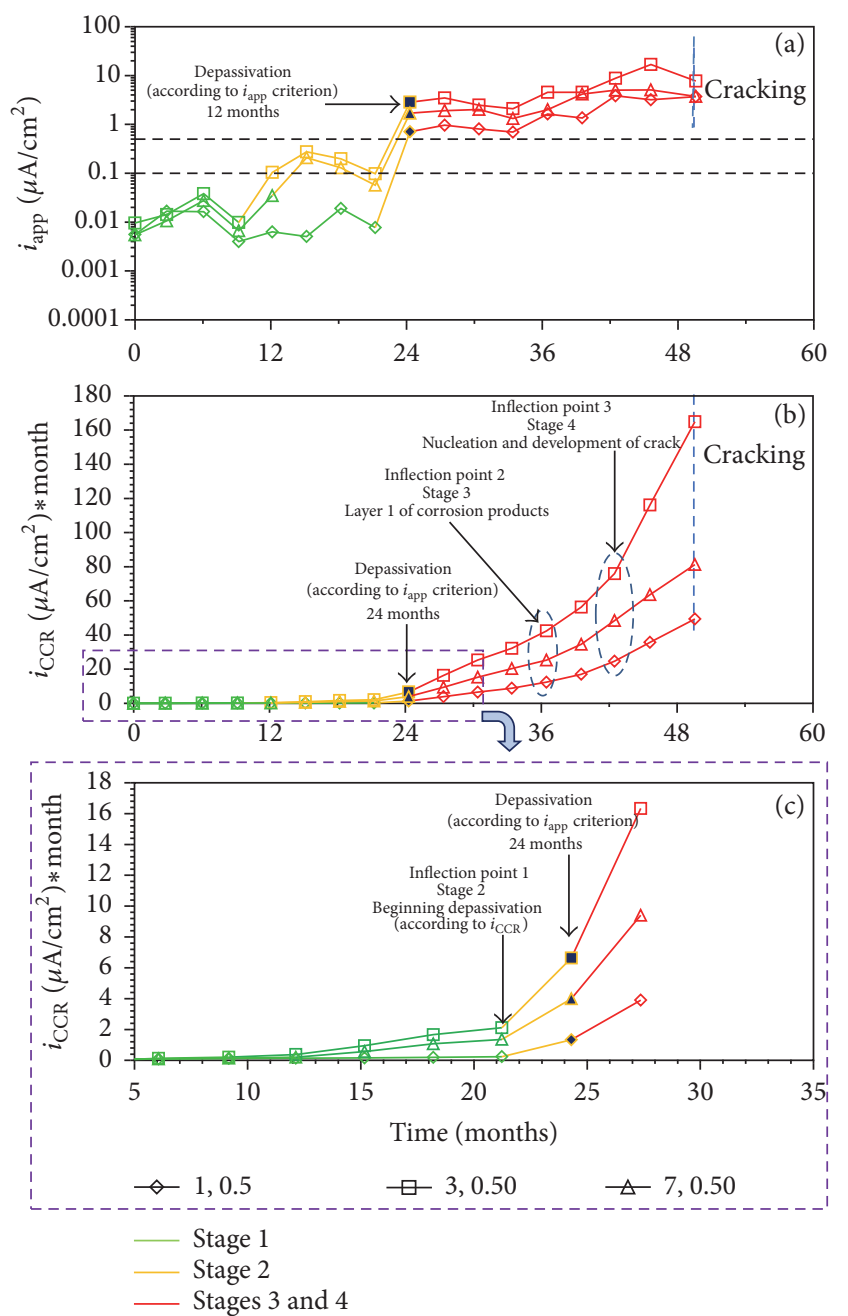

Figure 5: (a) Average $i_{\text {app }}$ and (b and c) $i_{\mathrm{CCR}}$ versus exposure time, $\mathrm{w} / \mathrm{c}$ ratio $=0.50$, and three CTs.

period but it already occurred at a later time according to the criteria of $i_{\text {app }}$. Under these conditions, it would be able, with the use of $i_{\mathrm{CCR}}$, to detect inflection changes and therefore anticipate a depassivation before it happens. The number of points maintaining a constant tendency after the inflection point is better observed at lower $\mathrm{w} / \mathrm{c}$ ratios. This would allow taking measures in economic terms. This period of depassivation is less notable in high $\mathrm{w} / \mathrm{c}$ ratios, since the kinetic of corrosion is very high in this natural marine environment and the step to the depassivation is very fast, as occurring in accelerated tests. Series of points with stable trend are longer at lower w/c ratios (slopes as detected by Andrade et al.) [13].

Stage 2 (depassivation). When the passive layer begins to break by action of chlorides, as in this case, $i_{\text {app }}$ values start drifting in the transition zone until a good part of the passive layer is broken. Figures 2(a)-6(a) show this trend with those data in yellow color. However, part of the difficulties on interpreting $i_{\text {app }}$ is recognizing the exact moment in which depassivation occurs. For this reason, it is considered
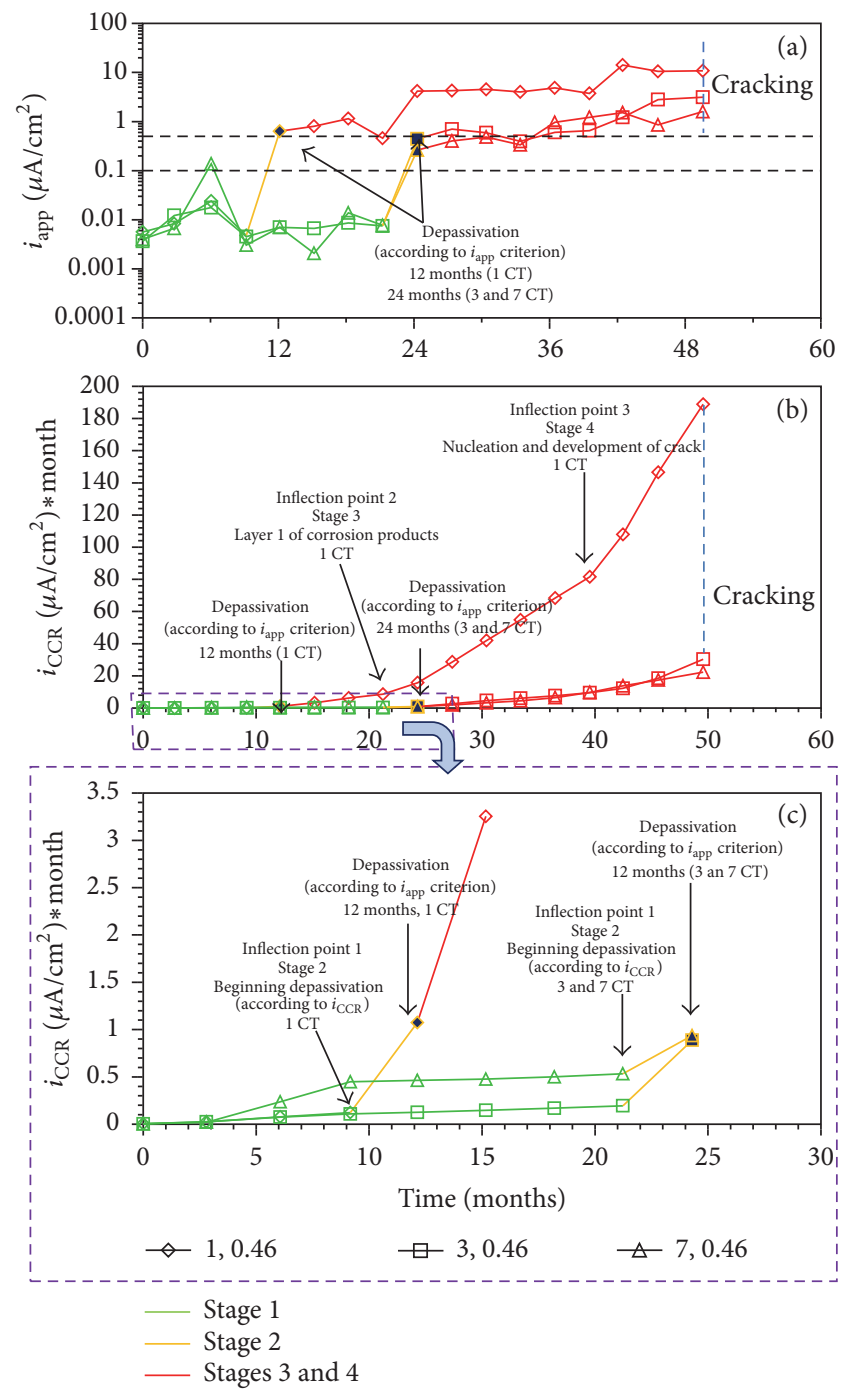

FIGURE 6: (a) Average $i_{\text {app }}$ and (b and c) $i_{\text {CCR }}$ versus exposure time, $\mathrm{w} / \mathrm{c}$ ratio $=0.46$, and three CTs.

that depassivation occurs when the $i_{\text {app }}$ values already do not return to the area of passivation (below the range 0.1$0.5 \mu \mathrm{A} / \mathrm{cm}^{2}$ ). Although this interpretation is correct, the fact is that it does not allow knowing whether the passivation will happen soon or not. It is therefore difficult to take preventive actions to control complete depassivation. This is where the utility of using cumulative corrosion comes. At the beginning of this stage (yellow dots in the data series in subsections (b) and (c) of Figures 2-6), the cumulative corrosion shows an inflection point from which a series of data following a stable trend that will end when the availability of oxygen is constrained initiates and another inflection point denotes the beginning of another stage (Stage 3 ).

Trends in stable increments of data can be seen in yellow color in Figures 2-6 (subsections (b) and (c)), noting a point in blue color on all of them that denotes the depassivation according to $i_{\text {app }}$. As shown, the points in blue were contained somewhere in the data sets in yellow, meaning that the inflection point is denoted the beginning of Stage 2 instead of 
the blue point detected with criterion of $i_{\text {app }}$. The utility, thus far, of cumulative corrosion is detected there on the inflection point before the blue one, which allows taking preventive actions to control depassivation from that moment provided that values of $i_{\text {app }}$ are still below the threshold most widely used $\left(0.1-0.5 \mu \mathrm{A} / \mathrm{cm}^{2}\right)$.

Stage 3 (layer 1 of corrosion products). The new point of inflection denotes the beginning of a layer formation of corrosion products as it is limiting the access of oxygen and chloride. Although these and the consequent layers of corrosion products are unstable, the truth is that the decrease of intensity in the cathodic reaction controls the process during some time where the increase in corrosion is stable and constant (series in red; Figures 2-6, subsections (b) and (c)). This process continues until a new inflection point appears that denotes again a new availability of oxygen and chlorides that gives place to the dissolution of the layer 1 of corrosion products.

Stage 4 (nucleation and development of cracks). There are physical and chemical reasons that may influence the breakdown of that layer 1 of Stage 3, some of them being the ease or difficulty of corrosion products migration in the matrix of concrete due to its quality [31], the nucleation and development of cracks, and the effect of other external agents as humidity, temperature, and so forth. [6, 32]. The above reasons can give place to subsequent processes during Stage 3 denoted by new inflection points and other series of stable data. In these cases, an inflection point may suggest the beginning of a crack, produced by stress caused by corrosion products which triggered the cracking and, in other cases, new corrosion layers produced by the permeability of concrete.

$i_{\mathrm{CCR}}$ has been used recently by some authors $[10-13,15]$. Previous findings from Andrade related to the utility of this tool were confirmed here with data from a natural marine environment.

One of the benefits of the cumulative corrosion technique is to offer a better definition among behaviors of variables with difficulty of discrimination. Traditionally, the w/c ratio is one of the variables most used to easily compare physical, chemical, and electrochemical behavior among concrete mixtures. However, it is uncommon to find comparisons among different variables such as CT or others. Therefore, in this manuscript, the CT was chosen as a variable of difficult discrimination, which under conditions of apparent corrosion rate does not usually show clear differences in behavior. By using the $i_{\mathrm{CCR}}$ tool, the effect of CT on the depassivation of the reinforcement can be observed (Figures 2-6).

On the other hand, the corrosion rate data in any of its representations, including the cumulative corrosion, are quantitative and kinetic, being thus clear and precise. The influence on them of thermodynamic parameters such as temperature is then implicit. This thermodynamic character, under representations such as the corrosion potential, is of a random nature [33].
From the above discussion, $i_{\mathrm{CCR}}$ can be considered an interesting tool to detect the four mentioned stages at least for the marine environment data reported.

\section{Conclusions}

The conclusions reported here apply to the specific conditions of the natural environment of Yucatán as well as to the materials tested. Other conditions of exposure and materials could be effective to improve the meaning and discussion of these findings.

CCR tool allowed the detection of inflection points that denote the beginning of the reported stages:

(a) Passivation

(b) Depassivation

(c) Formation and breakdown of corrosion layers

(d) Nucleation and development of cracks.

Stable series of data maintained among the inflection points correspond to the detected physic-chemical behavior.

$i_{\text {CCR }}$ tool was able to show important differences among $\mathrm{CT}$ and w/c ratios at early stages. This means to take cheap preventive actions to avoid depassivation and/or cracks.

$i_{\mathrm{CCR}}$ was also able to show the beginning of the depassivation period.

$i_{\mathrm{CCR}}$ allows predicting/anticipating the depassivation thanks to the first inflection point.

More information is needed to perform predictions after depassivation.

\section{Competing Interests}

The authors declare that there is no conflict of interests regarding the publication of this paper.

\section{Acknowledgments}

The authors wish to acknowledge CINVESTAV-IPN Unidad Mérida and CONACyT for partial support and Dr. A. Sagüés for his advice during the experiments design and cooperation.

\section{References}

[1] Y. Yuan, Y. Ji, and S. P. Shah, "Comparison of two accelerated corrosion techniques for concrete structures," ACI Structural Journal, vol. 104, no. 3, pp. 344-347, 2007.

[2] U. Angst, B. Elsener, C. K. Larsen, and Ø. Vennesland, "Critical chloride content in reinforced concrete-a review," Cement and Concrete Research, vol. 39, no. 12, pp. 1122-1138, 2009.

[3] C. Fang, K. Lundgren, L. Chen, and C. Zhu, "Corrosion influence on bond in reinforced concrete," Cement and Concrete Research, vol. 34, no. 11, pp. 2159-2167, 2004.

[4] P. Castro-Borges and J. M. Mendoza-Rangel, "Influence of climate change on concrete durability in Yucatan peninsula," Corrosion Engineering Science and Technology, vol. 45, no. 1, pp. 61-69, 2010. 
[5] M. Moreno, W. Morris, M. G. Alvarez, and G. S. Duffó, "Corrosion of reinforcing steel in simulated concrete pore solutions effect of carbonation and chloride content," Corrosion Science, vol. 46, no. 11, pp. 2681-2699, 2004.

[6] J. A. Cabrera-Madrid, M. Balancán-Zapata, A. A. TorresAcosta, and P. Castro-Borges, "Effect of tropical marine microclimates on depassivation and corrosion-induced cracking of reinforced concrete," International Journal of Electrochemical Science, vol. 9, no. 12, pp. 8211-8225, 2014.

[7] Y. Zhao, J. Yu, B. Hu, and W. Jin, "Crack shape and rust distribution in corrosion-induced cracking concrete," Corrosion Science, vol. 55, pp. 385-393, 2012.

[8] M. F. Montemor, A. M. P. Simões, and M. G. S. Ferreira, "Chloride-induced corrosion on reinforcing steel: from the fundamentals to the monitoring techniques," Cement and Concrete Composites, vol. 25, no. 4-5, pp. 491-502, 2003.

[9] C. Andrade and J. A. González, "Quantitative measurements of corrosion rate of reinforcing steels embedded in concrete using polarization resistance measurements," Materials and Corrosion, vol. 29, no. 8, pp. 515-519, 1978.

[10] C. Andrade, "Corrosion data interpretation in concrete structures," in Advances in Modeling Concrete Service Life: Proceedings of 4th International RILEM PhD Workshop held in Madrid, Spain, November 19, 2010, C. Andrade and J. Gulikers, Eds., vol. 3 of RILEM Bookseries, pp. 1-10, Springer, Dordrecht, The Netherlands, 2012.

[11] F. Pedrosa and C. Andrade, "Study of corrosion rate variability in indoor and outdoor specimens," in Proceedings of 4th International RILEM PhD Workshop on Advances in Modeling Concrete Service Life, C. Andrade and J. Gulikers, Eds., vol. 3 of RILEM Bookseries, pp. 33-42, Springer, Madrid, Spain, November 2010.

[12] N. Rebolledo and C. Andrade, "Study of corrosion rate variability in indoor and outdoor specimens," in Advances in Modeling Concrete Service Life: Proceedings of 4th International RILEM PhD Workshop held in Madrid, Spain, November 19, 2010, C. Andrade and J. Gulikers, Eds., vol. 3 of RILEM Bookseries, pp. 43-51, Springer, Dordrecht, The Netherlands, 2012.

[13] C. Andrade, J. Sanchez, J. Fullea, N. Rebolledo, and F. Tavares, "On-site corrosion rate measurements: 3D simulation and representative values," Materials and Corrosion, vol. 63, no. 12, pp. 1154-1164, 2012.

[14] O. Troconis De Rincón, J. C. Montenegro, R. Vera et al., "Reinforced concrete durability in marine environments DURACON project: long-term exposure," Corrosion, vol. 72, no. 6, pp. 824833, 2016.

[15] P. Castro-Borges, M. Balancán-Zapata, and A. López-González, "Analysis of tools to evaluate chloride threshold for corrosion onset of reinforced concrete in tropical marine environment of Yucatán, México," Journal of Chemistry, vol. 2013, Article ID 208619, 8 pages, 2013.

[16] P. Castro, A. A. Sagüés, E. I. Moreno, L. Maldonado, and J. Genescá, "Characterization of activated titanium solid reference electrodes for corrosion testing of steel in concrete," Corrosion, vol. 52, no. 8, pp. 609-617, 1996.

[17] M. A. Pech-Canul, A. A. Sagüés, and P. Castro, "Influence of counter electrode positioning on solution resistance in impedance measurements of reinforced concrete," Corrosion, vol. 54, no. 8, pp. 663-667, 1998.

[18] P. Castro, "The chloride threshold for corrosion onset of reinforced concrete in two tropical marine micro-climates of Yucatán, México," in Proceedings of the 3rd International
Conference: Concrete Under Severe Conditions, N. Banthia, K. Sakai, and O. Gjørv, Eds., pp. 151-158, London, UK, 2001.

[19] P. Castro, O. Troconis, and E. Pazini, "Chloride penetration profiles in marine environmen," in Proceedings of the 2nd CANMET/ACI International Conference, V. M. Malhotra, P. Helene, L. R. Prudencio Jr., and D. C. C. Dal Molin, Eds., SP 186, ACI Special Publication, 1999.

[20] V. G. Haach, G. Vasconcelos, and P. B. Loureno, "Influence of aggregates grading and water/cement ratio in workability and hardened properties of mortars," Construction and Building Materials, vol. 25, no. 6, pp. 2980-2987, 2011.

[21] C. Q. Li, "Corrosion initiation of reinforcing steel in concrete under natural salt spray and service loading-results and analysis," ACI Structural Journal, vol. 97, no. 6, pp. 690-697, 2000.

[22] L. Maldonado and L. Veleva, "Corrosivity category maps of a humid tropical atmosphere: the Yucatán Peninsula, México," Materials and Corrosion, vol. 50, no. 5, pp. 261-266, 1999.

[23] ISO 9223, Corrosion of Metals and Alloys. Corrosivity of Atmospheres. Classification, International Standardization Organization, Geneva, Switzerland, 2012 https://www.iso.org/obp/ui/ \#iso:std:iso:9223:ed-2:v1:en.

[24] C. Andrade, M. C. Alonso, and J. A. González, "An initial effort to use the corrosion rate measurements for estimating rebar durability," in ASTM STP 1065, N. S. Berke, V. Chaker, and D. Whiting, Eds., pp. 29-37, American Society for Testing and Materials, Philadelphia, Pa, USA, 1990.

[25] C. Andrade, V. Castelo, C. Alonso, and J. A. González, "The determination of the corrosion rate of steel embedded in concrete by the polarization resistance and AC impedance methods," in Corrosion Effect of Stray Currents and the Techniques for Evaluating Corrosion of Rebars in Concrete, V. Chaker, Ed., ASTM STP 906, pp. 43-63, American Society for Testing and Materials, Philadelphia, Pa, USA, 1984.

[26] L. Uller, O. Troconis de Rincón, I. Alanis et al., Manual for Inspecting, Evaluating and Diagnosing Corrosion in Reinforced Concrete Structures, DURAR Thematic Network XV.B. Durability of Rebars, CYTED Iberoamerican Program Science and Technology for Development, Maracaibo, Venezuela, 2000.

[27] P. Castro, L. Véleva, and M. Balancán, "Corrosion of reinforced concrete in a tropical marine environment and in accelerated tests," Construction and Building Materials, vol. 11, no. 2, pp. 7581, 1997.

[28] P. Castro, L. Maldonado, and R. de Coss, "Study of chloride diffusion as a corrosive agent in reinforced concrete for a tropical marine environment," Corrosion Science, vol. 35, no. 58, pp. 1557-1562, 1993.

[29] L. Maldonado and L. Veleva, "Corrosivity category maps of a humid tropical atmosphere: the Yucatán Peninsula, México," Materials and Corrosion, vol. 50, no. 5, pp. 261-266, 1999.

[30] R. E. Melchers and C. Q. Li, "Phenomenological modeling of reinforcement corrosion in marine environments," ACI Materials Journal, vol. 103, no. 1, pp. 25-32, 2006.

[31] J. M. Mendoza-Rangel, P. Castro-Borges, P. Quintana-Owen, M. Balancan-Zapata, and J. A. Cabrera-Madrid, "Chemical interactions in reinforced concrete exposed at a tropical marine environment," Journal of Chemistry, vol. 2015, Article ID 864872, 5 pages, 2015.

[32] A. A. Torres-Acosta and P. Castro-Borges, "Corrosion-induced cracking of concrete elements exposed to a natural marine environment for five years," Corrosion, vol. 69, no. 11, pp. 11221131, 2013. 
[33] P. Castro-Borges, J. A. Cabrera-Madrid, M. G. Balancán-Zapata, and A. A. Torres-Acosta, "Concrete cracking in two marine micro-climates," in Proceedings of the 2nd R.N. Raikar Memorial International Conference \& Banthia-Basheer International Symposium on Advances in Science \& Technology of Concrete, vol. 1 of Technical Papers, pp. 146-156, India Chapter of American Concrete Institute, December 2015. 

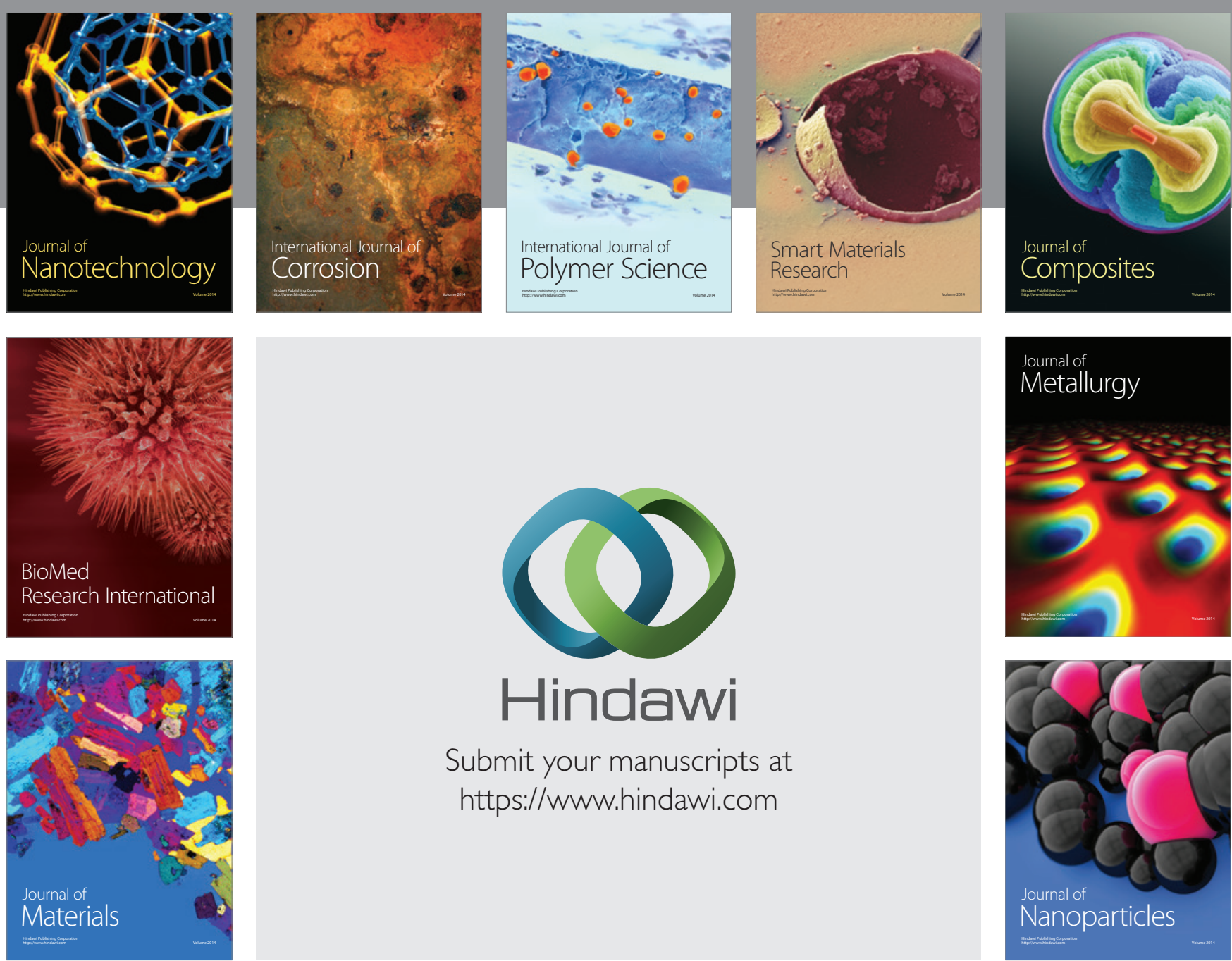

\section{Hindawi}

Submit your manuscripts at

https://www.hindawi.com

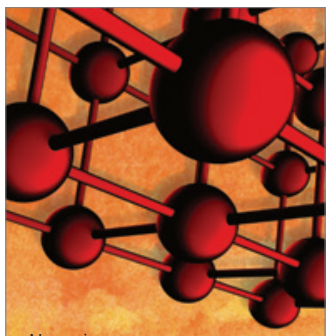

Materials Science and Engineering
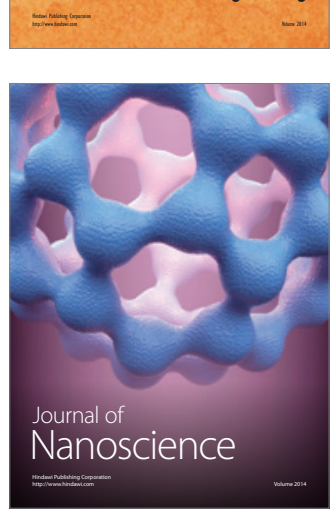
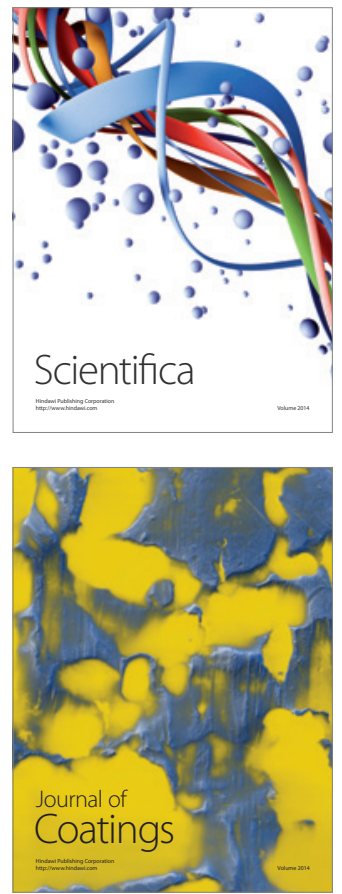
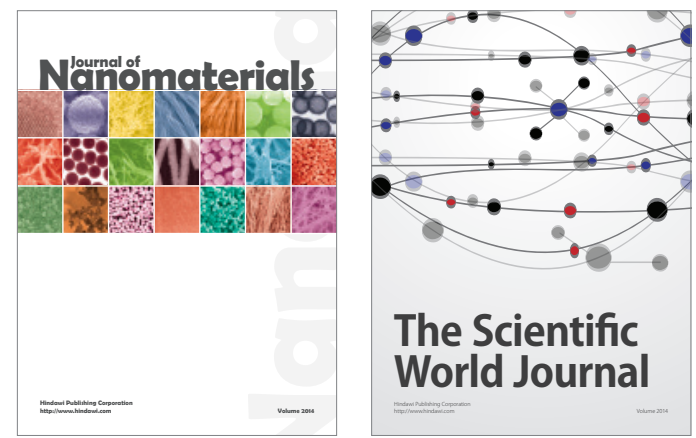

The Scientific World Journal
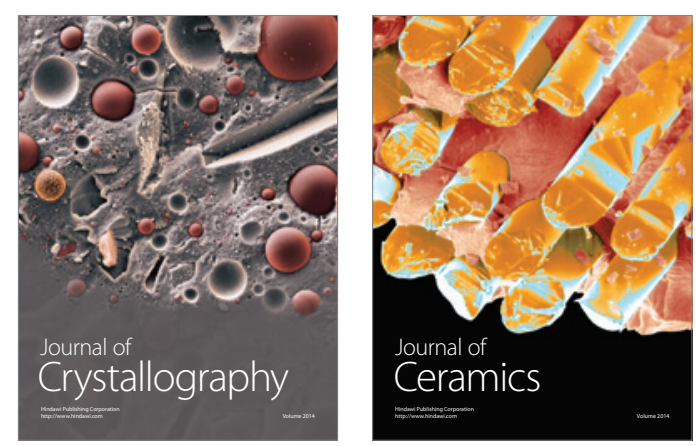
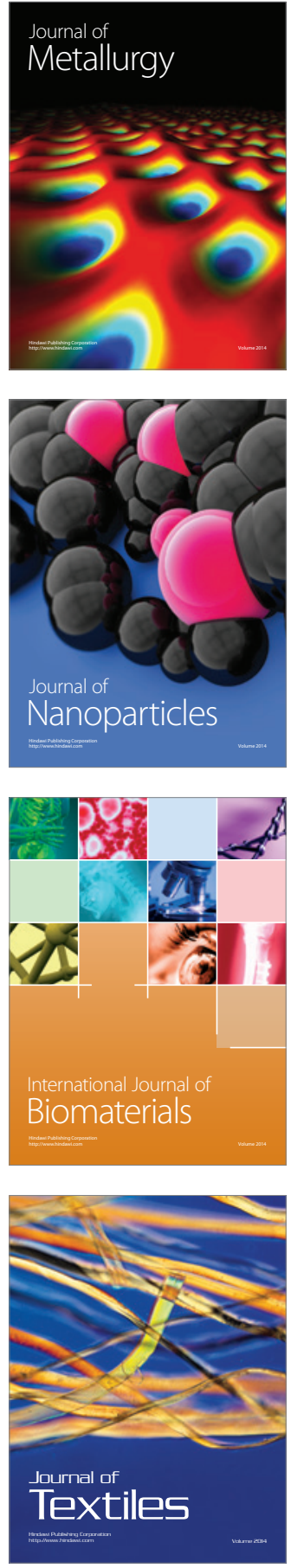